\title{
Nitric oxide involvement in the acrosome reaction triggered by leptin in pig sperm
}

Saveria Aquila ${ }^{1,3}$, Francesca Giordano ${ }^{2}$, Carmela Guido ${ }^{1,3}$, Vittoria Rago ${ }^{2}$ and Amalia Carpino ${ }^{2 *}$

\begin{abstract}
Background: Nitric oxide (NO) is a signaling molecule produced by intracellular nitric oxide synthase (NOS) enzymes. This free radical appears to affect sperm capacitation, a maturation step preceding acrosome reaction. Recent studies have reported leptin ability to promote capacitation and acrosome reaction in pig male gametes.

Methods: This study has investigated nitric oxide production in leptin-treated pig spermatozoa by fluorescenceactivated cell sorting, while the intracellular NOS isoforms were assessed by Western blot analysis. In addition, acrosome status of treated-spermatozoa was evaluated by FITC-PNA staining.

Results: Significant increases of nitric oxide levels and acrosome reaction extent were detected in leptin-treated spermatozoa, but both the effects were reversed in presence of L-NAME. Furthermore, the immunoblots of sperm extracts have evidenced three bands of $160 \mathrm{Kd}(\mathrm{bNOS}), \sim 130 \mathrm{Kd}$ (iNOS) and $135 \mathrm{Kd}$ (eNOS).

Conclusions: The identification of the three intracellular NOS isoforms suggests that pig spermatozoa could produce $\mathrm{NO}$, while the augmented nitric oxide levels in leptin-treated male gametes indicates the capacity of the hormone to induce nitric oxide production. Furthermore, the inhibitory effect of L-NAME and of Ab-ObR on the promotion of acrosome reaction triggered by leptin suggests a possible involvement of $\mathrm{NO}$ in the hormone action.
\end{abstract}

Keywords: acrosome reaction, leptin, nitric oxide, NOSs, pig spermatozoa

\section{Background}

The role of metabolic substances in the mechanisms controlling reproductive processes is emerging in the last years. Leptin is mainly known as a hormonal link between energy stores and energy homeostasis but it appears to be also involved in reproductive activity [1]. In the pig, leptin regulates reproductive functions at hypothalamus-pituitary level [2], but our recent works have also revealed its role in the control of peripheral structures. In fact, we have showed the expression of leptin and its receptor in pig testicular and epididymal tissues [3] as well as in pig spermatozoa [4]. Furthermore, we evidenced leptin capacity to affect pig sperm survival and capacitation. Capacitation is a crucial step of mammalian sperm maturation which induces biochemical and biophysical changes in sperm membrane, leading to a specialized exocytosis known as acrosome

\footnotetext{
* Correspondence: am_carpino@yahoo.it

${ }^{2}$ Department of Cell Biology, Faculty of Pharmacy, University of Calabria

87036 Arcavacata di Rende (Cosenza), Italy

Full list of author information is available at the end of the article
}

reaction [5]. Capacitation and acrosome reaction are two complex processes which appear to be controlled by cross-talks between different pathways [6-9] including the nitric oxide-dependent pathway $[10,11]$. Nitric oxide (NO) is a highly reactive signaling molecule, synthesized by intracellular NO-synthase (NOS) enzymes [12], which appears to regulate different sperm functions $[13,14]$.

The aim of the present study was to investigate the capacity of pig spermatozoa to produce NO in response to leptin treatment. Therefore, the expression of intracellular NOS enzymes has been also assessed and the possible involvement of NO in acrosome reaction triggered by leptin has been evaluated.

\section{Methods}

\section{Chemicals and antibodies}

Chemicals Laemmli sample buffer, pre-stained molecular weight marker, Percoll (colloidal PVP coated silica for cell separation), Earle's balanced salt solution, propidium iodide, fluorescein isothiocyanate-labeled peanut (Arachis
C Biomed Central

C 2011 Aquila et al; licensee BioMed Central Ltd. This is an Open Access article distributed under the terms of the Creative Commons Attribution License (http://creativecommons.org/licenses/by/2.0), which permits unrestricted use, distribution, and reproduction in any medium, provided the original work is properly cited. 
hypogaea) agglutinin (FITC-PNA) and all other chemicals were purchased from Sigma Chemical (Milan, Italy). Porcine leptin was purchased from Protein Laboratories Rehovot (Rehovot, Israel), acrylamide bisacrylamide was from Labtek Eurobio (Milan, Italy). Triton X-100, ECL Plus Western blotting detection system, Hybon$\mathrm{d}^{\mathrm{TM}}{ }^{\mathrm{E}} \mathrm{CL}^{\mathrm{TM}}$, were purchased from Amersham Pharmacia Biotech (Buckinghamshire, UK). Fluorescent probe 4,5-diaminofluorescein-2/diacetate (DAF 2/DA) and $N$ nitro- $L$-arginine methyl ester (L-NAME) were from Vinci Biochem,(Firenze, Italy)

Antibodies Mouse monoclonal anti-nitric oxide synthase inducible (iNOS) (N-9657), anti-nitric oxide synthase brain (bNOS)(N-2280) and anti-nitric oxide synthase endothelial (eNOS) (N-9532) were from Sigma Chemical (Milan, Italy). Polyclonal rabbit anti OBR(H300), peroxidase-coupled anti-mouse IgG and rabbit polyclonal anti $\beta$-actin were from Santa Cruz Biotechnology (Heidelberg, Germany).

\section{Animals and semen samples}

The investigation has been conducted on semen from 6 fertile male pigs (Sus scrofa domestica, Large White) kept at "Swine Artificial Insemination Centre" (Rende, Cosenza, Italy). The animals were 22 to 28 month-old and their weights were from 260 to $300 \mathrm{~kg}$. Individual fresh ejaculates were collected by the gloved hand method and filtered immediately by Universal Semen bags (Minitub, Tiefenbech, Germany). Semen was transported within half an hour to the laboratory, it was diluted 1:10 with TBS buffer and centrifuged on a discontinuous Percoll density gradient $(72 \% / 90 \%)$ to remove bacteria and debris [15].

\section{Sample treatments}

Percoll-purified spermatozoa were incubated with Earle's medium (uncapacitating medium) for 30 minutes at $39^{\circ} \mathrm{C}$ and $5 \% \mathrm{CO}_{2}$ without or with $10 \mathrm{nM}$ leptin, $0.7 \mathrm{mM} \mathrm{L}$ NAME. Some cells were also pre-treated $(15 \mathrm{~min})$ with the anti-OBR Ab (autocrine blockage). The dose of leptin was chosen on the basis of our previous findings [4].

\section{NO detection}

Intracellular NO was measured as previously described [16]. Briefly, leptin-treated spermatozoa were loaded with DAF-2/DA $(10 \mu \mathrm{M})$ and incubated $\left(120 \mathrm{~min}, 37^{\circ} \mathrm{C}\right)$ in the dark. Some of the samples were loaded with the NOS inhibitor, $L$-NAME (0.7 $\mathrm{mM}), 30 \mathrm{~min}$ prior to DAF-2/ DA loading. Care was taken to prevent exposure to light throughout the rest of the experiment as the probe is light-sensitive. After incubation with DAF-2/DA the cells were analyzed by fluorescence-activated cell sorting (FACS analyzer) (excitation wavelength $488 \mathrm{~nm}$ and emission wavelength $530 \mathrm{~nm}$ ) at a single-cell level and data were analyzed using Cell Quest software (Becton Dickinson, NJ, USA). The mean fluorescence intensity of the analyzed sperm cells was determined after gating the cell population by forward and side scatter signals. In total, 25000 events were acquired, but non-sperm particles and debris were excluded by prior gating, thereby limiting undesired effects on overall fluorescence. The final gated populations usually consisted of $15000-$ 20000 sperm cells.

The experiments were repeated at least four times for each sample.

\section{Western blot analysis}

Western blot analysis was used to identify NOS enzymes in sperm samples. Percolled spermatozoa were washed twice with Earle's balanced salt solution and then were centrifuged for $5 \mathrm{~min}$ at $5000 \times \mathrm{g}$. The pellet was resuspended in lysis buffer as previously described [17]. Equal amounts of proteins $(80 \mu \mathrm{g})$ were boiled for $5 \mathrm{~min}$, separated by $10 \%$ polyacrylamide gel electrophoresis, transferred to nitrocellulose sheets and probed with an appropriate dilution of anti-iNOS (1:1000), anti-bNOS (1:3000) and anti-eNOS (1:3000) antibodies. The bound of the secondary antibody was revealed with the ECL Plus WB detection system according to the manufacturer's instructions. Negative controls were prepared using tissue lysates, where antigens were previously removed by preincubation with specific antibodies (1 hour at room temperature) and subsequently immunoprecipitated with protein A/G-agarose. $\beta$-actin served as a control for equal loading. The experiments were repeated at least four times for each sample.

Human breast cancer cells, MCF7, expressing the three NOS isoforms, were used as control. MCF7, obtained from American Type Culture Collection (ATCC), were cultured in a $25 \mathrm{~cm}^{2}$ cell culture flask containing DMEM supplemented with $10 \%$ FBS and 10 units of penicillin and $10 \mu \mathrm{g} / \mathrm{ml}$ of streptomycin, at $37^{\circ} \mathrm{C}$, in a humidified incubator containing $5 \% \mathrm{CO}_{2}$.

\section{Acrosome reaction}

Spermatozoa incubated with leptin, combined or not with $L$-NAME or Ab-OBR, were re-suspended in unsupplemented Earle's medium (Earle's balanced salt solution without $\mathrm{Ca}, \mathrm{Mg}$, Phenol red and $\left.\mathrm{NaHCO}_{3}\right)\left(5 \times 10^{6}\right.$ spermatozoa/ml), were placed in a conical tube and cultured for 2 hours in an atmosphere of $5 \% \mathrm{CO}_{2}$ in air at $39^{\circ} \mathrm{C}$. Spermatozoa incubated only with Earle's medium were used as control. Then acrosomal status was monitored using the acrosome-specific fluorochrome fluorescein isothiocyanate-labeled peanut (Arachis hypogaea) agglutinin (FITC-PNA) in conjunction with DNA-specific fluorochrome propidium iodide (PI) as a viability test [18]. Briefly, sperm suspension $\left(1 \times 10^{6} \mathrm{ml}\right)$ was exposed to 
FITC-PNA $(10 \mu \mathrm{g} / \mathrm{ml})$ and propidium iodide $(12 \mu \mathrm{mol} / \mathrm{l})$ for 5 minutes at $39^{\circ} \mathrm{C}$ and then fixed by adding $1 \mathrm{ml}$ of $12.5 \%(\mathrm{w} / \mathrm{v})$ paraformaldehyde in $0.5 \mathrm{~mol}$ Tris/l ( $\mathrm{pH} 7.4$ ). The slides were immediately examined with an epifluorescence microscope (Olympus BX41) with a multiple fluorescence filter (U-DM-DA/FI/TX2) observing a minimum of 200 spermatozoa per slide (100x objective). Acrosomal status was assessed according to the staining patterns.

\section{Staining patterns}

Spermatozoa with a nuclear red PI staining were considered as dead cells while sperm cells without PI staining were considered as live cells.

Live spermatozoa were classified in 2 main categories on the basis of the FITC-PNA staining as follows: i) acrosome-reacted cells with uniform green FITC-PNA fluorescence of acrosome cap ii) acrosome-intact cells without any fluorescence. Values were expressed as percentage. Four replicate experiments were performed for each semen sample.

\section{Statistical analysis}

Data, presented as mean \pm SEM, were evaluated by the one-way analysis of variance (ANOVA). The differences in mean values were calculated at a significance level of $P \leq 0.05$. The Wilcoxson test was used after ANOVA as post hoc test.

\section{Results}

\section{NO production by pig spermatozoa}

Incubation of pig spermatozoa with $10 \mathrm{nM}$ leptin induced a significant increase of intracellular NO levels (Figure 1B) with respect to control sperm (Figure 1A), while pre-treatment of spermatozoa with the NOS inhibitor, $L$-NAME, reversed the leptin effect (Figure 1C). The DAF-2/DA fluorescence data are also expressed as mean fluorescence (percentage of control, control adjusted to 100\%) (Figure 1D)

\section{Western blot analysis}

The immunoblots of sperm extracts showed three NOS bands: $\sim 160 \mathrm{kDa}, \sim 130 \mathrm{kDa}$ and $\sim 135 \mathrm{kDa}$ corresponding to bNOS, iNOS and eNOS respectively (Figure 2: lanes 1 and 2). Three NOS bands at the same mobility were observed in the positive control (Figure 2: lane MCF7). The negative controls were unlabelled.

\section{Acrosome reaction in leptin-treated pig spermatozoa}

Figure 3A shows a representative fluorescence pattern of pig spermatozoa stained with FITC-PNA + PI for the assessment of acrosome status and sperm viability, after leptin treatment. No significant difference was observed in the incidence of dead spermatozoa between treatedspermatozoa and control sperm.
A higher percentage of acrosome-reacted cells (FITCPNA positive cells) was detected in $10 \mathrm{nM}$ Lep-treated spermatozoa $(19 \pm 2 \%)$ with respect to control spermatozoa $(8 \pm 3 \%)$, while $L$-NAME reversed the acrosome reaction extent triggered by leptin $(12 \pm 3 \%)$ as well as Ab-OBR (11 $\pm 3 \%)$ (Figure 3B)

\section{Discussion}

Low and controlled concentrations of nitric oxide play an important role in sperm physiology, while excessive NO levels are detrimental [19].

Nitric oxide(NO) is a free radical involved in the intraand intercellular signaling mechanisms. NO is generated from the oxidation of L-arginine to L-citrulline by 3 isoforms of NADPH-dependent NO synthases (NOS) [12]. Two constitutive $\mathrm{Ca}^{2+}$ - dependent isoforms are known, i.e. neuronal or brain NOS (n/bNOS) firstly found in neurons and endothelial NOS (eNOS) firstly found in endothelial cells [20]. In addition, one inducible $\mathrm{Ca}^{2+}$ independent isoform (iNOS) has been also described [21], firstly identified in macrophages.

The NOS-NO system appears to be implicated in different events leading to acquisition of fertilizing ability. The NOS isoforms were detected in different mammalian spermatozoa such as in mouse [22], in bull [23] and in human spermatozoa [24,25], while NO was able to affect sperm motility, capacitation and acrosome reaction in the mouse [26], in the hamster [27], in the bull $[28,29]$ and also in the human [30-35].

Concerning porcine spermatozoa, NOS enzymes were immunolocalized in male testicular germ cells [36] and NOS isoforms were detected in testis extract [37] but their expression in ejaculated spermatozoa is still unknown. However, NO appears to play a role in functional activity of the male gamete. In fact, it has been reported that $L$ arginine and geldamycin (a heat shock protein 90-specific inhibitor) are able to induce capacitation and acrosome reaction in boar spermatozoa, trough the NO signal pathway $[18,38]$.

Recent studies by our own and others have revealed that leptin and insulin, two hormones linked to energy homeostasis, can be involved in porcine sperm biology $[4,39]$. Particularly, we have detected leptin and its receptor in pig spermatozoa, localizing them at acrosomal level, and have evidenced the hormone ability to promote capacitation and acrosome reaction [4].

The present study has been addressed to investigate if NO signalling could mediate leptin promotion of pig acrosome reaction. On the basis of our previous findings [4] we have selected the dose of leptin (10 nm leptin) inducing the best stimulatory response on pig sperm capacitation. In addition, to better investigate the effect of leptin on intracellular NO production, we have used 

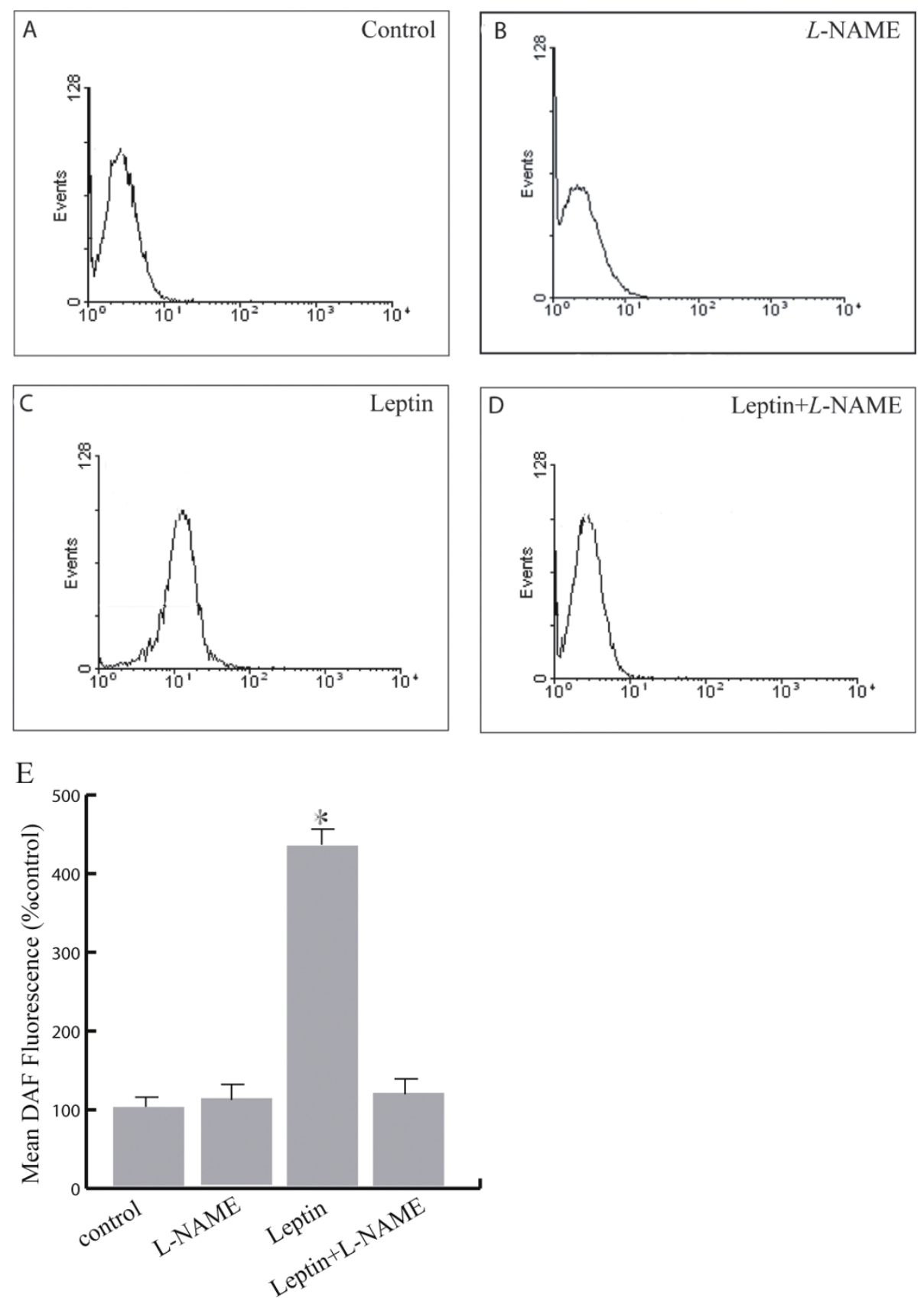

Figure 1 Representative histograms of DAF fluorescence in pig sperm. (A): Control sperm. (B):spermatozoa incubated with L-NAME. (C): leptin-treated sperm.(D): leptin-treated sperm in presence of L-NAME. (E): data above reported which are expressed as mean fluorescence (percentage of control, control adjusted to 100\%). Values are mean percentage \pm SD. $\left({ }^{*} p<0.05\right)$.

uncapacitated spermatozoa (such as in our previous work) avoiding the interference of the high NO levels generated by spermatozoa in capacitating condition [32]

Our investigation has identified, for the first time, the three NOS isoforms (bNOS, eNOS and iNOS) in pig ejaculated spermatozoa indicating the potential ability of the male gamete to synthesize NO. Then, we have shown a significant increase of intracellular NO production in leptin-treated spermatozoa, suggesting that NO could mediate the hormone action. Therefore, we have detected sperm acrosome reaction induced by leptin in presence or not of a NOS inhibitor ( $L-\mathrm{NAME}$ ) and of Ab-ObR to block leptin from binding to its specific receptors.

As expected, leptin was able to promote acrosome reaction but the NOS inhibitor and $\mathrm{AB}-\mathrm{ObR}$ reversed the effect of the hormone. These results suggest the 


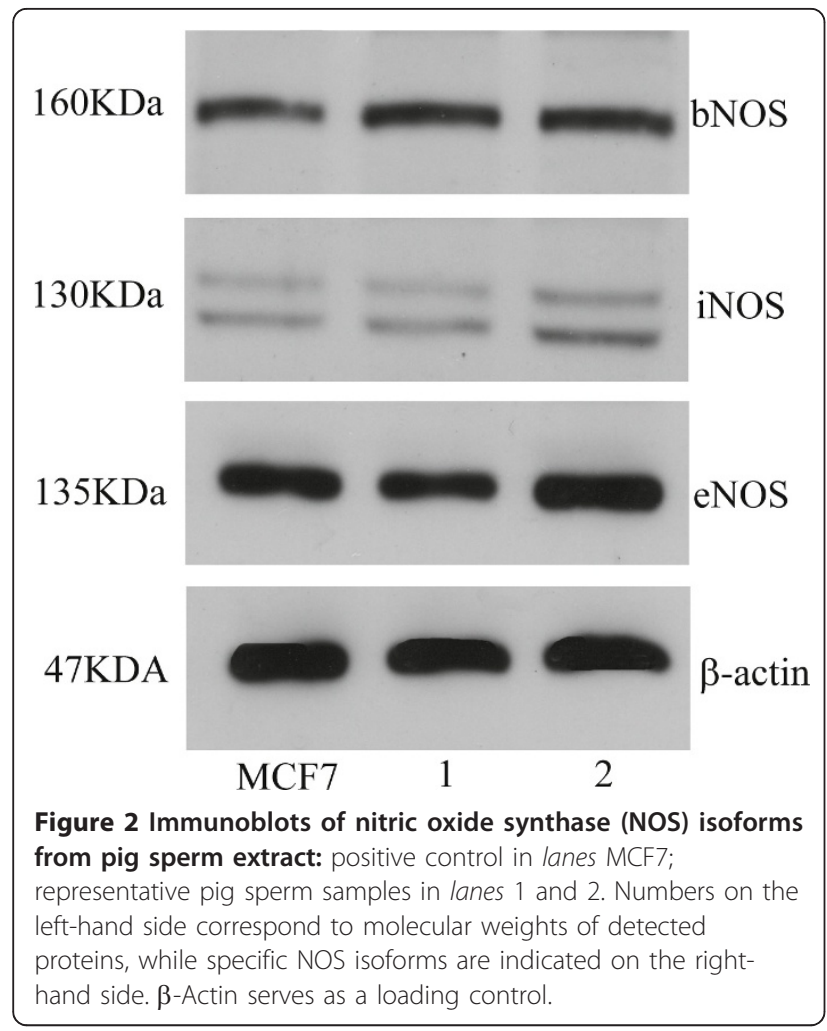

implication of the NOS-NO system in the promoter action of leptin on acrosome reaction of pig sperm. A similar result has been recently reported in human spermatozoa [40].

In our previous work [4] we investigated the main transduction pathways regulated by leptin in pig spermatozoa suggesting that extracellular signal-regulated kinase (ERK) $1 / 2$ and phosphatidylinositol Phosphate Kinase 3 (PI3K)/Akt are implicated in the hormone action. In fact, leptin, through its receptor, was able to activate positively ERK1/2 as well as Akt. Because it has been reported that ERK1/2 and PI3K/Akt can regulate NOS activity, via serine phosphorylation [41-43], it is reasonable to hypothesize that the signalling cascade, induced by leptin, could cause NOS activation in pig spermatozoa leading to intracellular NO increase. Furthermore, NOS activation is also calcium-dependent, therefore it can be speculated that intracellular calcium stores could be mobilized by leptin in pig male gametes for the synthesis of NO.

\section{Conclusions}

The identification of the three intracellular NOS isoforms suggests that pig spermatozoa could produce NO, while the augmented nitric oxide levels in leptin- treated male gametes indicates the capacity of the hormone to induce nitric oxide production. Furthermore, the inhibitory effect of $L$-NAME and of Ab-ObR on the promotion of

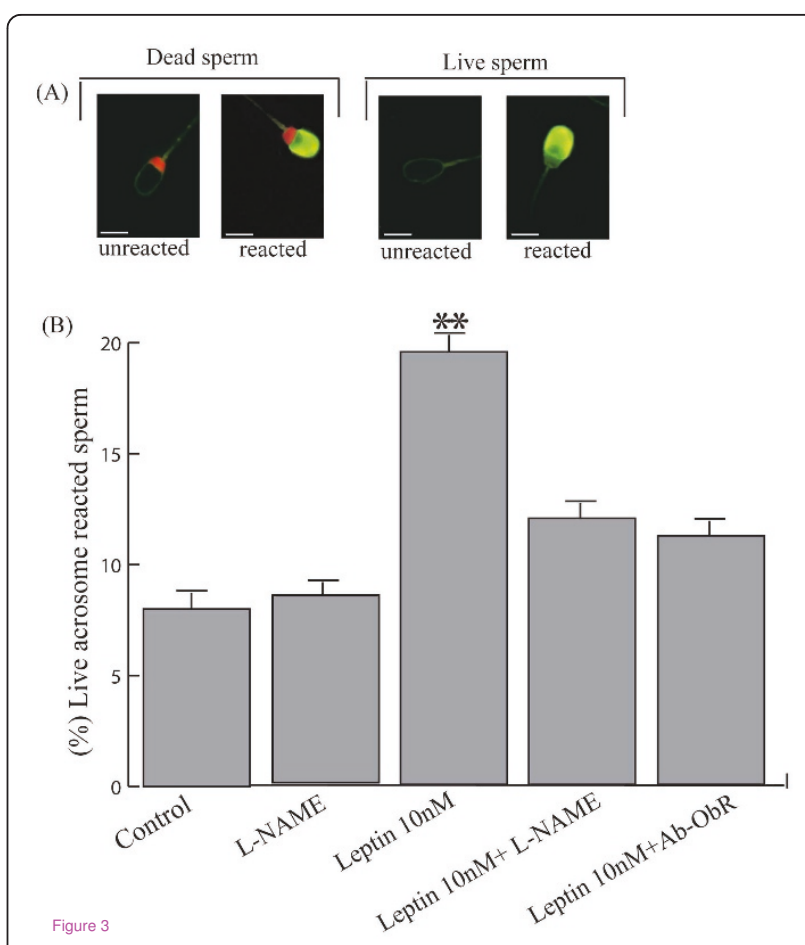

Figure 3 Acrosome reaction in leptin-treated pig sperm. (A) Representative FITC-PNA fluorescence pattern of spermatozoa incubated with $10 \mathrm{nM}$ leptin. Scale bars: 5 Hm. (B) Incidence of positive acrosome reaction in control spermatozoa, spermatozoa incubated with L-NAME, spermatozoa incubated with $10 \mathrm{nM}$ leptin, spermatozoa incubated with $10 \mathrm{nM}$ leptin in presence of L-NAME and spermatozoa incubated with $10 \mathrm{nM}$ leptin+ Ab-ObR. Values are mean percentage $\pm S D(* * p<0.01)$.

acrosome reaction triggered by leptin suggests a possible involvement of $\mathrm{NO}$ in the hormone action.

\section{Acknowledgements}

The authors thank Dr Rocco Panza, chief of the Swine Artificial Insemination Centre, APA, Cosenza (Italy), who provided animals for sample collections. Our special thank also to prof. Antonietta Martire for the English reviewing of this manuscript. This work was supported by MURST and Ex 60\% -2009

\section{Author details}

'Department of Pharmaco-Biology, University of Calabria 87036 Arcavacata di Rende (Cosenza), Italy. ${ }^{2}$ Department of Cell Biology, Faculty of Pharmacy, University of Calabria 87036 Arcavacata di Rende (Cosenza), Italy. ${ }^{3}$ Centro Sanitario. University of Calabria 87036 Arcavacata di Rende (Cosenza) Italy.

\section{Authors' contributions}

SA the author responsible for performing the experiments and participating in the analysis and interpretation of data.

FG carried out the FACS experiments.

CG carried out the pig sperm treatment and WB analysis.

VR carried out the acosome reaction experiment.

AC the author responsible for conception, design, analysis and interpretation of data as well as of drafting manuscript. All authors read and approved the final manuscript.

\section{Competing interests}

The authors declare that they have no competing interests. 
Received: 15 June 2011 Accepted: 4 October 2011

Published: 4 October 2011

\section{References}

1. Barash IA, Cheung CC, Weigle DS, Ren H, Kabigting EB, Kuijper JL, Clifton DK, Steiner RA: Leptin is a metabolic signal to the reproductive system. Endocrinology 1996, 137:3144-3147.

2. Caprio M, Fabbrini E, Isidori AM, Aversa A, Fabbri A: Leptin in reproduction. Trends Endocrinol Metab 2001, 12:65-72.

3. Rago V, Aquila S, Guido C, Carpino A: Leptin and its receptor are expressed in the testis and in the epididymis of young and adult pigs. Anat Rec (Hoboken) 2009, 292:736-745.

4. Aquila S, Rago V, Guido C, Casaburi I, Zupo S, Carpino A: Leptin and leptin receptor in pig spermatozoa: evidence of their involvement in sperm capacitation and survival. Reproduction 2008, 136(1):23-32

5. Bedford MJ, Cross NL: Sperm capacitation. In encyclopedia of reproduction. Volume 4. Edited by: Knobil E, Neill JD. Academic, San Diego; 1999:597-602.

6. de Lamirande E, LeclerC P, Gagnon C: Capacitation as a regulatory event that primes spermatozoa for the acrosome reaction and fertilization. Mol Hum Reprod 1997, 3:175-94

7. Leclerc P, de Lamirande E, Gagnon C: Interaction between Ca2+, cyclic $3^{\prime}, 5^{\prime}$ adenosine monophosphate, the superoxide anion, and tyrosine phosphorylation pathways in the regulation of human sperm capacitation. J Androl 1998, 19:434-443.

8. Bailey JL: Factors regulating sperm capacitation. Syst Biol Reprod Med 2010, 56(5):334-48

9. Fraser LR: The "switching on" of mammalian spermatozoa: molecular events involved in promotion and regulation of capacitation. Mol Reprod Dev 2010, 77(3):197-208.

10. Zhang H, Zhou QM, Li XD, Zhao WP, Wang YL, Liu H, Li N: Ginsenoside Re promotes human sperm capacitation through nitric oxide-dependent pathway. Mol Reprod Dev 2007, 74:497-501.

11. De Lamirande $E$, Lamothe $G$ : Reactive oxygen-induced reactive oxygen formation during human sperm. Free Radic Biol Med 2009, 46(4):502-510.

12. Palmer R M, Ashton DS, Moncada S: Vascular endothelial cells synthesize nitric oxide from L-arginine. Nature 1988, 333:664-666.

13. Herrero MB, Gagnon C: Nitric Oxide: a novel mediatore of sperm function. J Androl 2001, 22(3):349-356.

14. Roessner C, Paasch U, Glander HJ, Grunewald S: Activity of nitric oxide synthase in mature and immature human spermatozoa. Andrologia 2010, 42(2):132-7.

15. Kuster CE, Hess RA: Althouse, Immunofluorescence reveals ubiquitination of retained distal cytoplasmic droplet on ejaculated porcine spermatozoa. J Androl 2004, 25:340-347.

16. Lampiao F, Strijdom H, du Plessis SS: Direct nitric oxide measurement in human spermatozoa: flow cytometric analysis using the fluorescent probe, diaminofluorescein. Int J Androl 2006, 29:564-567.

17. Aquila S, Sisci D, Gentile ME, Middea E, Siciliano L, Andò S: Human ejaculated spermatozoa contain active P450 aromatase. J Clin Endocrinol Metab 2002, 87:3385-3390.

18. Funahashi H: Induction of capacitation and acrosome reaction of boar spermatozoa by L-arginine and nitric oxide synthesis associated with the anion transport system. Reproduction 2002, 124:857-864

19. Herrero $M B$, de Lamirande $E$, Gagnon C: Nitric oxide is a signaling molecule in spermatozoa. Curr Pharm Des 2003, 9(5):419-425.

20. Knowles RG, Moncada S: Nitric oxide synthases in mammals. Biochem J 1994, 298:249-58.

21. Förstermann U, Closs El, Pollock JS, Nakane M, Schwarz P, Gath I, Kleinert H: Nitric oxide synthase isozymes. Characterization, purification, molecular cloning, and functions. Hypertension 1994, 23:1121-1131.

22. Herrero MB, Goin JC, Canteros MG, Franchi AM, Perez Martinez S, Polak JM, Viggiano JM, F Gimeno MA: The nitric oxide synthase of mouse spermatozoa. FEBS Lett 1997, 411:39-42.

23. Meiser H, Schulz R: Detection and localization of two constitutive NOS isoforms in bull spermatozoa. Anat Histol Embryol 2003, 32:321-325.

24. Herrero MB, Perez Martinez S, Viggiano JM, Polak JM, Gimeno MAF: Localization by indirect immunofluorescence of nitric oxide synthase in mouse and human spermatozoa. Reprod Fertil Dev 1996, 6:931-934.

25. O'Bryan MK, Zini A, Cheng CY, Schlegel PN: Human sperm endothelial nitric oxide synthase expression: correlation with sperm motility. Fertil Steril 1998, 70(6):1143-1147.
26. Herrero MB, Cebral E, Boquet M, Viggiano JM, Vitullo A, Gimeno MA: Effect of nitric oxide on mouse sperm hyperactivation. Acta Physiol Pharmacol Ther Latinoam 1994, 44(3):65-69.

27. Kameshwari DB, Siva AB, Shivaji S: Inhibition of in vitro capacitation of hamster spermatozoa by nitric oxide synthase inhibitors. Cell Mol Biol 2003, 49:421-428.

28. Rodriguez PC, O'Flaherty CM, Beconi MT, Beorlegui NB: Nitric oxide induces acrosome reaction in cryopreserved bovine spermatozoa. Andrologia 2005, 37(5):166-172.

29. Rodriguez PC, Valdez LB, Zaobornyj T, Boveris A, Beconi MT: Nitric Oxide and superoxide anion production during Heparin-Induced capacitation in cryopreserved bovine spermatozoa. Reprod Dom Anim 2011, 46(1):74-81.

30. Lewis SEM, Donnelly ET, Sterling ELS, Kennedy MS, Thompson W, Chakravarthy U: Nitric oxide synthase and nitrite production in human spermatozoa: evidence that endogenous nitric oxide is beneficial to sperm motility. Mol Hum Reprod 1996, 2:873-878.

31. Herrero MB, de Lamirande E, Gagnon C: Nitric oxide regulates human sperm capacitation and protein-tyrosine phosphorylation in vitro. Biol Reprod 1999, 61(3):575-581.

32. Herrero MB, Chaatterjee S, Lefievre L, de Lamirande E, Gagnon C: Nitric oxide interacts with the CAMP pathway to modulate capacitation of human spermatozoa. Free Radic Biol Med 2000, 29:522-536.

33. Revelli A, Costamagna C, Moffa F, Aldieri E, Ochetti S, Bosia A, Massobrio M, Lindblom B, Ghigo D: Signaling pathway of nitric oxide-induced acrosome reaction in human spermatozoa. Biol Reprod 2001, 64:1708-1712.

34. Zhang H, Zhou QM, Li XD, Duan X, Min FL, Liu B, Yuan ZG: Ginsenoside Re increases fertile and asthenozoospermic infertile human sperm motility by induction of nitric oxide synthase. Arch Pharm Res 2006, 29:145-151.

35. Miraglia E, De Angelis F, Gazzano E, Hassanpour H, Bertagna A, Aldieri E, Revelli A, Ghigo D: Nitric oxide stimulates human sperm motility via activation of the cyclic GMP/protein kinase $\mathrm{G}$ signaling pathway. Reproduction 2011, 141:47-54

36. Kim HC, Byun JS, Lee T K, Jeong CW, Ahn M, Shin T: Expression of nitric oxide synthase isoforms in the testes of pigs. Anat Histol Embryol 2007, 36:135-138.

37. Ambrosino A, Russo D, Lamanna C, Assisi L, Rizzo M, Vittoria A, Cecio A: Isoforms of nitric oxide synthase in the pig testis. Acta Vet BRNO 2003, 72:493-498.

38. Hou ML, Huang SY, Lai YK, Lee WC: Geldanamycin augments nitric oxide production and promotes capacitation in boar spermatozoa. Anim Reprod Sci 2008, 104:56-68.

39. Carpino A, Rago V, Guido C, Casaburi I, Aquila S: Insulin and IR-beta in pig spermatozoa: a role of the hormone in the acquisition of fertilizing ability. Int J Androl 2010, 33(3):554-562.

40. Lampiao F, Du Plessis SS: Insulin and Leptin enhance human sperm motility, acrosome reaction and nitric oxide production. Asian J Androl 2008, 10:799-807.

41. Cai H, Li Z, Davis ME, Kanner W, Harrison DG, Dudley SC: Akt-dependent phosphorylation od serine ${ }^{1179}$ and mitogen-activated protein kinase kinase/extracellular signal-regulated kinase $1 / 2$ cooperatively mediate activation of the endothelial nitric-oxide synthase by hydrogen peroxide. Mol Pharmacol 2003, 63:325-331.

42. Lorenz M, Wessler S, Follmann E, Michaelis W, Düsterhöft T, Baumann G, Stangl K, Stangl V: A constituent of green tea, epigallocatechin-3-gallate, activates endothelial nitric oxide synthase by a phosphatidylinositol-3$\mathrm{OH}$-kinase-cAMP-dependent protein kinase-, and Akt-dependent pathway and leads to endothelial-dependent vasorelaxation. $J$ Biol Chem 2004, 279(7):6190-6195.

43. Chen CC, Ke WH, Ceng LH, Hsieh CW, Wung BS: Calcium and phosphatidynolositol 3-kinase/Akt-dependent activation of endothelian nitric oxide synthase by apigenin. Life Sci 2010, 87:743-749.

doi:10.1186/1477-7827-9-133

Cite this article as: Aquila et al:: Nitric oxide involvement in the acrosome reaction triggered by leptin in pig sperm. Reproductive Biology and Endocrinology 2011 9:133. 